九州大学学術情報リポジトリ

Kyushu University Institutional Repository

\title{
The Effect of G0/Ti0_2 Thin Film During Photodegradation of Methylene Blue Dye
}

\author{
Azani, Azliza \\ Center of Excellence Geopolymer \& Green Technology (CEGeoGTech), Faculty of Chemical \\ Engineering Technology, Universiti Malaysia Perlis (UniMAP)
}

Dewi Suriyani Che Halin

Center of Excellence Geopolymer \& Green Technology (CEGeoGTech), Faculty of Chemical Engineering Technology, Universiti Malaysia Perlis (UniMAP)

Mohd Mustafa Al Bakri Abdullah

Center of Excellence Geopolymer \& Green Technology (CEGeoGTech), Faculty of Chemical Engineering Technology, Universiti Malaysia Perlis (UniMAP)

Kamrosni Abdul Razak

Center of Excellence Geopolymer \& Green Technology (CEGeoGTech), Faculty of Chemical Engineering Technology, Universiti Malaysia Perlis (UniMAP)

他

https://doi.org/10.5109/4491643

出版情報：Evergreen. 8 (3)，pp.556-564，2021-09. 九州大学グリーンテクノロジー研究教育センター バージョン：

権利関係 : 


\title{
The Effect of GO/TiO 2 Thin Film During Photodegradation of Methylene Blue Dye
}

\author{
Azliza Azani, *, Dewi Suriyani Che Halin ${ }^{1}$, Mohd Mustafa Al Bakri Abdullah ${ }^{1}$, \\ Kamrosni Abdul Razak ${ }^{1}$, Mohd Fairul Sharin Abdul Razak ${ }^{1}$, Muhammad Mahyid \\ din Ramli ${ }^{1,2}$, Mohd Arif Anuar Mohd Salleh ${ }^{1}$, V Chobpattana ${ }^{3}$ \\ ${ }^{1}$ Center of Excellence Geopolymer \& Green Technology (CEGeoGTech), Faculty of Chemical Engineering \\ Technology, Universiti Malaysia Perlis (UniMAP), 02600 Jalan Kangar-Arau, Perlis, Malaysia. \\ ${ }^{2}$ Faculty of Electronic Engineering Technology, Univerisi Malaysia Perlis, Pauh Putra Campus, 02600 Arau, \\ Perlis, Malaysia.
}

${ }^{3}$ Department of Materials and Metallurgical Engineering, Faculty of Engineering, Rajamangala University of Technology Thanyaburi (RMUTT), Thailand.

E-mail: dewisuriyani@unimap.edu.my

(Received February 13, 2021; Revised July 9, 2021; accepted July 25, 2021).

\begin{abstract}
Titanium (IV) isopropoxide (TTIP) was used to synthesize $\mathrm{GO} / \mathrm{TiO}_{2}$ thin films using a sol-gel spin-coating method onto a glass substrate, undergoing an heat tretment at $350{ }^{\circ} \mathrm{C}$. Several amounts of graphene oxide (GO) $(0-20 \mathrm{mg})$ were weighed into a sol solution of $\mathrm{TiO}_{2}$ to produce $\mathrm{GO} / \mathrm{TiO}_{2}$ thin films. The thin film samples were characterized by X-ray diffraction (XRD) to analyze the samples' phase and by scanning electron microscopy (SEM) to analyze the samples' microstructure. Physical testing such as water contact angle (WCA) was analyzed using an optical microscope with J-Image software. In contrast, the optical band gap and photodegradation of methylene blue under sunlight irradiation of the thin film was analyzed using UV-VIS spectrophotometry. $\mathrm{GO}_{5}$ thin film sample showed low-intensity anatase phase formation, where the microstructure revealed a larger surface area with the addition of GO. WCA reveals that GO/ $\mathrm{TiO}_{2}$ thin film exhibits super hydrophilic properties where the angle decreases from $37.83^{\circ}$ to $4.11^{\circ}$. The optical result shows that GO has improved the absorption edges by expanding into visible regions. Moreover, due to the existence of $\mathrm{GO} 3.30 \mathrm{eV}$ band gap energy of $\mathrm{TiO}_{2}$ decreases from to $3.18 \mathrm{eV}$ obtained by $\mathrm{GO}_{5}$. The improved adsorption edge allows $\mathrm{Ti}^{3+}, \mathrm{O}_{2}$ and interstitial states to be formed in low valence states with energy underneath than in the $\mathrm{TiO}_{2}$ band gap. Therefore, the photodegradation of methylene blue (MB) dye increases from $48 \%$ to $59 \%$ in the $\mathrm{GO} / \mathrm{TiO}_{2}$ thin film.
\end{abstract}

Keywords: Photodegradation, methylene blue, thin-film, water contact angle, graphene oxide

\section{Introduction}

Titanium dioxide $\left(\mathrm{TiO}_{2}\right)$ has been shown as the most studied and successful material, including as a photocatalyst during the photodegradation of organic pollutants for the remediation of environmental pollutions 1)2). Furthermore, $\mathrm{TiO}_{2}$ has also been rapidly used to convert the solar energy and dissociation of water ${ }^{3)}$. It has many applications because of its unique properties, including electronic devices, gas sensors, solar cells, optical applications, as well as antibacterial and catalyst material ${ }^{455}$. Currently, $\mathrm{TiO}_{2}$ is also used as a self-cleaning surface. Under the self-cleaning application, two separate mechanisms are involved, which are photocatalysis and hydrophobic. Under the photocatalysis process, the chemical structure of organic pollutants and other impurities on the surface is broken down by absorbing sunlight. $\quad \mathrm{TiO}_{2}$ usually exhibits super-hydrophilic properties under ultraviolet light ${ }^{6}$. The hydrophilic property from the $\mathrm{TiO}_{2}$ surface leads to creating the water plates on the surface by reducing the contact angle that eliminates the contamination ${ }^{7}$. Instead of the many advantages of $\mathrm{TiO}_{2}$, unfortunately, it also has disadvantages. The disadvantages are a vast band gap of $3.2 \mathrm{eV}$, which limits its versatility towards the usage of $\mathrm{TiO}_{2}$ under the irradiation of natural sunlight ${ }^{8}$. $\quad \mathrm{TiO}_{2}$ photocatalyst with just a little UV fraction of solar light can be excited.

Furthermore, pristine $\mathrm{TiO}_{2}$ will face a high electronhole recombination rate, resulting in poor efficiency of photocatalytic degradation reactions and low quantum 
yield ${ }^{9)}$. Besides that, a lack of utilization of sunlight that reduced the ROS (Reactive Oxygen Species) formation has to be improved. The lack of utilization of sunlight occurs since $\mathrm{TiO}_{2}$ exhibits self-cleaning activity under light irradiation due to the oxygen vacancies and ROS formation by excitation of electron and hole ${ }^{10}$ ). Evidently, various attempts for improving $\mathrm{TiO}_{2}$ towards visible light regions has been made.

Modification of $\mathrm{TiO}_{2}$ photocatalyst is necessary to solve the above disadvantages by coupling semiconductors, doping of nitrogen, carbon, sulphur, and noble metals ${ }^{11)}$. The doping process is one of the promising modifications to enhance the photoresponse of $\mathrm{TiO}_{2}$. In the past decade, $\mathrm{TiO}_{2}$ coupled with metal oxides was undergo a research studies which related to the photocatalytic activity such as $\mathrm{SnO}_{2}{ }^{12,13)}, \mathrm{Fe}_{2} \mathrm{O}_{3}{ }^{14,15)}$, and some carbon nanostructure ${ }^{16)}$ were performed to enhance the photocatalytic activity of $\mathrm{TiO}_{2}$. The outcome of doping on photocatalytic activity depends on several aspects such as type, concentration of ions, and ion doping techniques ${ }^{17)}$. Graphene oxide (GO) is an excellent replacement for noble metal that can be used as the dopants onto $\mathrm{TiO}_{2}$. It is also well known that GO is an attractive carbon material with unique physicochemical properties. The properties include magnificent conductivity, very good mechanical strength and broad specific surface area ${ }^{18)}$. Besides that, GO consists of a huge number of functional groups that contain oxygens. This can serve as favourable anchoring centres and nucleation sites for precursors or active species. In addition, $\mathrm{TiO}_{2}$ doped graphene has been considered a potential photocatalyst in the purification of air and water. It was also mentioned that $\mathrm{TiO}_{2} /$ graphene has a few times higher photocatalytic activity in contrast to the pure $\mathrm{TiO}_{2}$. Self-cleaning technology can make full use of the excellent photocatalysis of the graphene semiconductor system and the transparency of graphene characteristics ${ }^{19)}$.

Thus, many researchers focus on the preparation of $\mathrm{GO} / \mathrm{TiO}_{2}$ instead of the composite fabrication onto the immobilized system. For example, Baig et al., (2019) prepared $\mathrm{GO} / \mathrm{TiO}_{2}$ films by coating the graphene layer in the first place and later deposited the $\mathrm{TiO}_{2}$ on top of that layer ${ }^{20)}$. In another previous study by Vallejo et al., (2019), $\mathrm{TiO}_{2}$ thin film was further improved by adding $0.15,0.26$, 0.51 and 1.1 (w/w \%) graphene oxide to improve the band gap values of $\mathrm{TiO}_{2}$ from $3.21 \mathrm{eV}$ to $2.45 \mathrm{eV}$. Therefore, the thin film's photocatalytic activity performance was also improved due to the presence of GO. GO is also understood as an electron-donating material whereby the approach has improved the catalyst efficiency, which is $\mathrm{TiO}_{2}$. This kind of donating materials reduces electronhole pairs' recombination rate by increasing the chargecarrier mobility. The effect on the physical chemistry properties is important where the yield of photodegradation was boost due to the existance of $\mathrm{GO}^{21)}$.

Meanwhile, A.Jalaukan et al., (2019) reported that titanium dioxide was deposited first. Then, the graphene oxide layer was deposited onto $\mathrm{TiO}_{2}$ at different concentrations to investigate the consequences of graphene oxide layer addition to the morphological, structural, antibacterial, photocatalytic activity and selfcleaning properties of $\mathrm{TiO}_{2}$ thin films ${ }^{22}$. For this reason, it has been published that $\mathrm{GO} / \mathrm{TiO}_{2}$ nanocomposites can also serve as a dye remover in aqueous solutions. Specifically, the sol-gel process shows an excellent method to produce a layer with a good property for coating applications. This includes transparent and thin under multiple component oxide layers on the numerous substrates, for example glass plates, alumina plates, stainless-steel plates, ceramic tiles, and many more. Therefore, sol-gel based fabrication has been proposed as a low-cost alternative to fabricating optical devices ${ }^{23}$.

In this research, a modification has been made to $\mathrm{TiO}_{2}$ thin film by adding various amounts of graphene oxide onto a glass substrate under the production of $\mathrm{TiO}_{2}$ via sol-gel method. Then, the fresh $\mathrm{TiO}_{2}$ sol-gel solution was doped with different concentrations of graphene oxide followed by the heat treatment of annealed process on the hydrophilicity of films. Under this system, it may prohibit the aggregation of $\mathrm{TiO}_{2}$. It may prolong the photocatalytic time with the better photocatalytic process due to the synergistic effects between $\mathrm{GO}$ and $\mathrm{TiO}_{2}$ where the performance of the thin film based on the photocatalytic activity could be enhanced. This research has contributed to the new self-cleaning materials as well as a better understanding of modified $\mathrm{TiO}_{2}$ as self-cleaning material.

\section{Experimental}

\subsection{Preparation of $\mathrm{GO} / \mathrm{TiO}_{2}$ thin film}

Analytical grade of graphene oxide powder, titanium (IV) isopropoxide (TTIP) $97 \%$, absolute ethanol ( $99.9 \%$ ), and acetic acid (glacial) $100 \%$ utilized in this synthesis were used as it is.

A glass slide with the dimension of $25 \mathrm{~mm}$ (length) $\mathrm{x}$ $25 \mathrm{~mm}$ (width) was used as a substrate to deposite the thin film. The glass substrates were washed for 20 minutes with acetone in an ultrasonic bath and then cleaned with distilled water and put to dry at room temperature. After that, those substrates were ready to be coated. The $\mathrm{TiO}_{2}$ sample was synthesized from TTIP and absolute ethanol via the sol-gel process ${ }^{24)}$.

Firstly, an amount of graphene oxide powder $(0,5,10$, $15,20 \mathrm{mg}$ ) was weighed and mixed with a small amount of absolute ethanol. Then, it was sonicated for 30 minutes in the ultrasonic bath. By using a proportion of $1 \mathrm{ml}$ of TTIP to $20 \mathrm{ml}$ of absolute ethanol, TTIP was diluted with absolute ethanol under a stirring process using a magnetic stirrer for 5 minutes. After that, the previously mixed GO was poured into the TTIP:ethanol solution and proceeded with vigorous stirring for 1 hour. Afterwards, acetic acid $(\sim 0.30 \mathrm{ml})$ was carefully added into the solution by dropwise technique under a vigorous stirring condition until a clear solution was obtained. The acetic acid must 
be added to stabilize the solution and control the sol-gel precursor's hydrolysis reaction. A sample without GO was also prepared as a controlled sample.

When the sol-gel prepared was ready, the spin coating technique was used to deposit the sol-gel solution onto the clean glass substrate for 30 seconds at a speed of $800 \mathrm{rpm}$. The glass substrate was coated with three layers to ensure that the sol-gel solution will entirely cover the surface of the glass. The coated thin film was left at room temperature for a few minutes to dry before coating with the next coating layer. Then, an annealed temperature at $350{ }^{\circ} \mathrm{C}$ will be set for the annealing process onto coated glass. The soaking time is 1 hour, while the rate of annealing is $10^{\circ} \mathrm{C} /$ minute. According to Dideikin et al., (2019), the typical temperature range used for thermal reduction of graphene oxide is within $400-1200^{\circ} \mathrm{C}{ }^{25}$. Therefore, $350^{\circ} \mathrm{C}$ annealing temperature was used to prepare the thin film. Finally, $\mathrm{GO} / \mathrm{TiO}_{2}$ thin films were obtained

\subsection{Characterizations}

The crystalline phase of the thin film was determined using the X-Ray Diffraction (XRD) technique with Bruker D8 Advance X-Ray Diffractometer using $\mathrm{Cu}$ tube, $\mathrm{K} \alpha$ ( $\lambda$ $=1.54056 \AA$ ) at $40.0 \mathrm{kV}$, current of $30 \mathrm{~mA}$ and scanning rate of $2^{\circ} \mathrm{min}^{-1} \mathrm{n}$ a range of $5^{\circ}<2 \theta<70^{\circ}$. The microstructure and morphology of the thin film were analyzed using the Scanning Electron Microscope (SEM) origin from Japan with model of JEOL JSM-6460LA. Before analyzing the sample in the SEM, JEOL JFC 1600 model of Auto Fine Coater was used to coat the sample with palladium $(\mathrm{Pd})$. The analysis was done under high vacuum conditions with a voltage of $20 \mathrm{kV}$ and $20000 \mathrm{x}$ magnification. The hydrophilic properties of $\mathrm{TiO}_{2}$ and $\mathrm{GO} / \mathrm{TiO}_{2}$ thin films were discovered from water contact angle analysis. The contact angle of the water drop between water and the film surface was first photographed with an optical microscope and then measured using the Image-J software. Hydrophilic properties are essential to determine the self-cleaning mechanism, which will occur on the $\mathrm{GO} / \mathrm{TiO}_{2}$ thin film surface. The optical properties of $\mathrm{TiO}_{2}$ and $\mathrm{GO} / \mathrm{TiO}_{2}$ thin films, such as the absorption rate and the amount of energy gap, were measured using a UV-Visible spectrophotometer (Perkin Elmer, Lamda 25) at 300 to $500 \mathrm{~nm}$ wavelength, respectively. The calculation of the optical energy gap for the thin film was also performed using the Tauc equation given in Eq. (1):

$$
(\alpha h v)=\mathrm{A}(h v-\mathrm{Eg})^{1 / 2}
$$

\subsection{Photodegradation of Methylene Blue}

Methylene blue dye is understood to be a non-toxic and convenient dye used to measure the photocatalytic performance of $\mathrm{TiO}_{2}$ and $\mathrm{GO} / \mathrm{TiO}_{2}$ thin film samples. The photocatalytic degradation performance of the thin films were measured by the degradation or decolourization of methylene blue at the wavelength of $664 \mathrm{~nm}$ based on the absorbance value of methylene blue at individual irradiation time intervals. Before the photocatalysis process occurs, the thin film samples were put in the opaque container or unlighted condition for 60 minutes to allow the absorption /desorption to stablize. After 60 minutes, the thin films were exposed to sunlight for the photocatalytic activity to take place. The percent of methylene blue degradation was determined using Eq.(2) given by:

$\%$ dye degradation $=\left(\frac{C 0-C}{C 0}\right) \times 100 \%$

\section{Results and Discussions}

\subsection{Phase analysis}

Based on the XRD diffarctrogram of $\mathrm{TiO}_{2}$ and $\mathrm{GO}_{5}$ thin films in Fig. 1, the results exhibited that only a brookite phase was formed in $\mathrm{TiO}_{2}$ thin film. Characterize diffraction peaks shown at $2 \theta=33.5^{\circ}$ indicates the presence of brookite $\mathrm{TiO}_{2}$ brookite referred to the standard ICDD card No. 00-029-1360, which corresponded to the (121) plane. Meanwhile, $\mathrm{GO}_{5}$ thin film diffraction peaks showed the mixed phases of brookite and anatase. Here, $2 \theta$ value of $24.8^{\circ}$ was attributed to the anatase (101) plane, and $2 \theta$ value of $33.5^{\circ}$ was attributed to the brookite $\mathrm{TiO}_{2}$ (201) plane (ICDD Card No. 01-070-8501). Besides that, a single peak recorded at $2 \theta=21.9^{\circ}$ indicates the presence of silicon resulted from the substrate. According to Fig. 1, adding GO into $\mathrm{TiO}_{2}$ somehow contributed to the development of the $\mathrm{TiO}_{2}$ mixed phase of anatase and brookite. The diffraction pattern of $\mathrm{GO}_{5}$ shows that the intensity of $\mathrm{TiO}_{2}$ anatase increases and $\mathrm{TiO} 2$ brookite phase decreases.

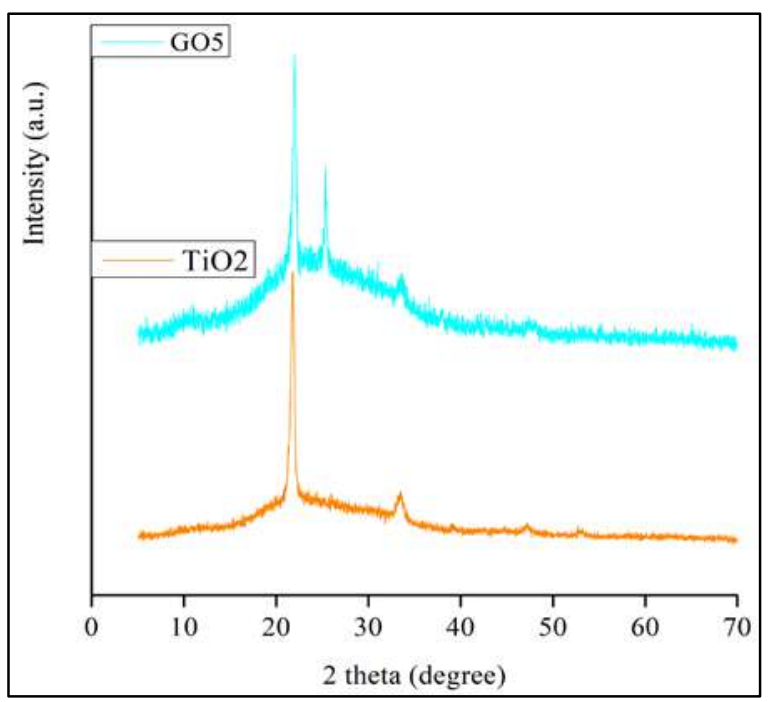

Fig. 1: XRD diffractogram of $\mathrm{TiO}_{2}$ and $\mathrm{GO}_{5}$ thin films.

Obviously, annealing temperature is a facctor contributed to the formation of anatase phase with poor crystallinity that occurred at $350^{\circ} \mathrm{C}$ annealing temperature 26). Meanwhile, further annealing up to $500-600^{\circ} \mathrm{C}$ will slowly transform brookite $\mathrm{TiO}_{2}$ to anatase $\mathrm{TiO}_{2}{ }^{27}$. 
Fischer et al., (2017) stated that the anatase phase of $\mathrm{TiO}_{2}$ would grow better at higher temperatures ${ }^{28)}$. In addition, Johari et al., (2019) previous research also stated that for brookite formation a spin-coating deposition at low temperature is preferable ${ }^{29)}$.

Meanwhile, there were no peaks identified to indicate the presence of GO. This suggests that GO exists in the form of nanoplates or lamellae that are well dispersed between $\mathrm{TiO}_{2}$ particles ${ }^{30}$ ). Therefore, it cannot be detected by X-ray diffraction due to the small amount of GO. This can be verified in the morphology analysis. Gascho et al., (2019) also reported that the absensce of peak at $2 \theta=10^{\circ}$ that represent GO in the films in X-ray diffractograms, indicating a partial reduction of the GO. This probably caused by the sheet of graphene oxide stacking again partially in the material ${ }^{31}$.

\subsection{Microstructure analysis}

The SEM analysis performed on $\mathrm{TiO}_{2}$ and $\mathrm{GO}_{5}$ thin films were analyzed based on the microstructure formation in Fig. 2. Fig.2 (a) images reveal that the particles of $\mathrm{TiO}_{2}$ are spherical shape showing a basic morphology of $\mathrm{TiO}_{2}$ particles presenting a combination of various sizes particles with a flower-like formation of synthesized $\mathrm{TiO}_{2}$ photocatalyst ${ }^{3)}$. Besides that, it can be observed that the distribution of $\mathrm{TiO}_{2}$ in the thin film sample are homogeneous due to the sol-gel process. On the other hand, Fig. 2(b) shows the microstructure of $\mathrm{GO}_{5}$ thin film, revealing that GO in the thin film obviously affects the films' microstructure. The particles of $\mathrm{TiO}_{2}$ were coated by GO. The SEM also showed that by adding $\mathrm{GO}$, the particle size of $\mathrm{TiO}_{2}$ becomes bigger and exhibits a unique microstructure where the GO layer covered the $\mathrm{TiO}_{2}$. The findings were consistent with Ni, Wang, Huang, $\mathrm{Lu}, \& \mathrm{Xu}$, (2014), who investigated the microstructure of $\mathrm{TiO}_{2}$ with GO addition. The authors stated that GO covered the $\mathrm{TiO}_{2}$ surface tightly, where the covered $\mathrm{TiO}_{2}$ surface area expand with GO and its content ${ }^{32}$. Appropriate addition of GO enhances light absorption by having the separation of photogenerated electrons and holes and a larger specific area. In contrast, photo carriers' mobility was reduced, while the adsorption of light was also disturbed if too much GO was introduced in the samples ${ }^{33)}$. The large particle size of $\mathrm{TiO}_{2}$ will increase the surface area, allowing more photocatalytic activity to occur; therefore, the self-cleaning properties will be more efficient.

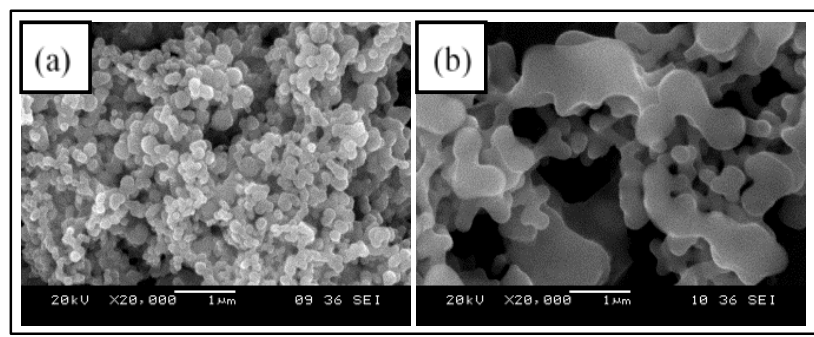

Fig. 2: SEM images of (a) $\mathrm{TiO}_{2}$ and (b) $\mathrm{GO}_{5}$ thin films.

\subsection{Water contact angle analysis}

Fig. 3 displays the water contact angles of $\mathrm{TiO}_{2}$ and $\mathrm{GO} / \mathrm{TiO}_{2}$ thin films. The $\mathrm{TiO}_{2}$ film exhibits a water contact angle of $37.83^{\circ}$. Interestingly, when $5 \mathrm{mg}$ GO $\left(\mathrm{GO}_{5}\right)$ was added to $\mathrm{TiO}_{2}$ film, the water contact angle drastically dropped to $4.11^{\circ}$. This indicated the super hydrophilicity properties of lesser than $5^{\circ}$ water contact angle. However, a further increase in the amount of GO increased the water contact angle. Results showed that when a higher GO loading was added, such as 10mg, $15 \mathrm{mg}$ and $20 \mathrm{mg}\left(\mathrm{GO}_{10}, \mathrm{GO}_{15}\right.$ and $\left.\mathrm{GO}_{20}\right)$, the water contact angle also slightly increased to $9.39^{\circ}, 13.15^{\circ}$ and $56.48^{\circ}$, respectively. The decrement in water contact angle is due to the amount of GO added to the films. Good selfcleaning thin film is interrelated to good hydrophilic properties where the contaminants are easily removed from the surface ${ }^{34)}$.

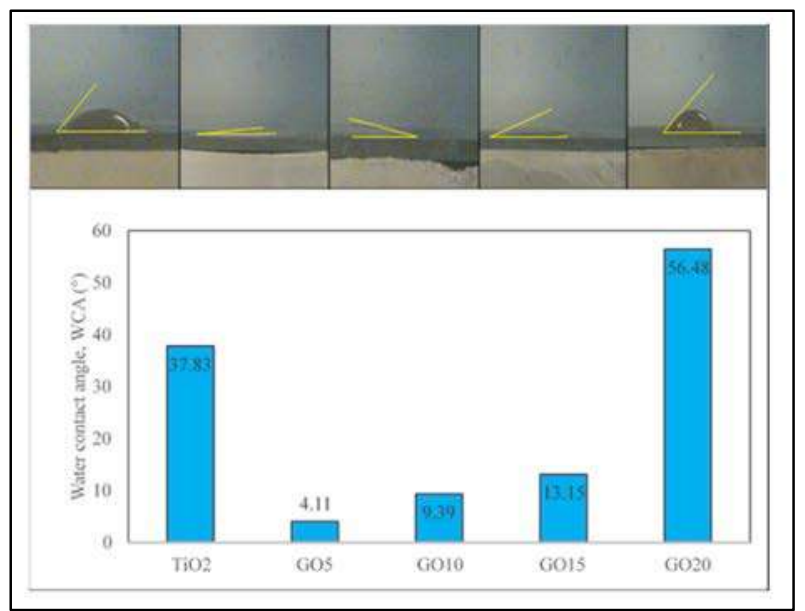

Fig. 3: Water contact angle of $\mathrm{TiO}_{2}$ and $\mathrm{GO} / \mathrm{TiO}_{2}$ thin films.

\subsection{Optical properties analysis}

The adsorption spectra in Fig. 4 shows the absorbance of $\mathrm{TiO}_{2}$ and $\mathrm{GO} / \mathrm{TiO}_{2}$ thin film samples at the wavelength ranging between 300-500 nm at a different amount of GO. For $\mathrm{TiO}_{2}$ thin film, the adsorption is about 0.7 (arbitrary unit). In contrast, at a wavelength of $380 \mathrm{~nm} \mathrm{GO}$ increased the absorption to about 1.7 (arbitrary unit). The adsorption of light was significantly affected by the addition of $\mathrm{GO}^{35}$ ). The samples with the addition of GO show high adsorption in the UV range. Previous research also stated that nanoparticles incorporated in carbon nanofibers have an advantage in adsorption and fast degradation of dye. This enhances the photocatalytic activity resulting in enhanced self-cleaning properties of the thin film ${ }^{36,37)}$. Besides that, with the increasing amount of GO used, it can be seen clearly that the adsorption edge has been shifted in the adsorption spectra. $\mathrm{GO} / \mathrm{TiO}_{2}$ thin film cut-off wavelength of has been extended into visible regions compared to $\mathrm{TiO}_{2}$ thin film. The cut-off wavelength can be determined by sketching a tangent line next to the edge of the adsorption line. The intersection point to get the cut-off wavelength value and the 
absorption spectrum and the wavelength axis on the cut edge ${ }^{38)}$.

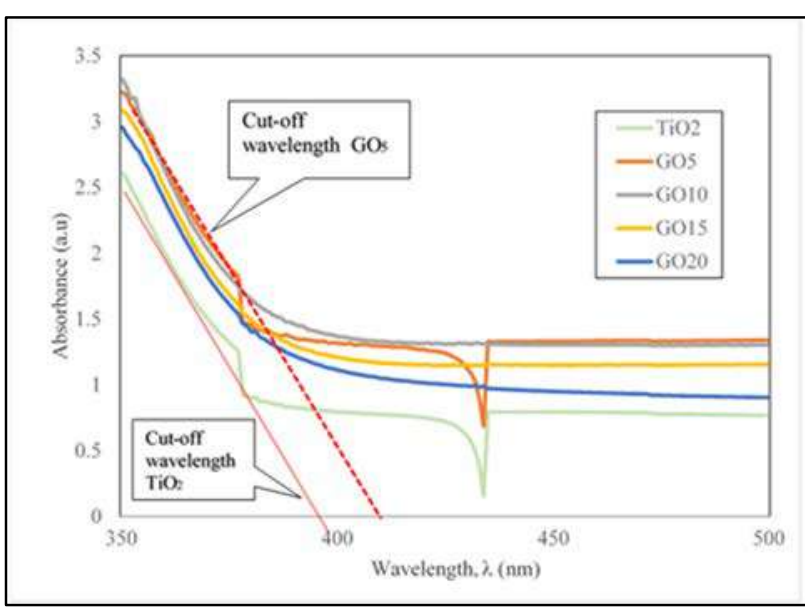

Fig. 4: Changes in adsorption by wavelength for $\mathrm{TiO}_{2}$ thin films with different GO weights.

The cut-off wavelength of $\mathrm{GO} / \mathrm{TiO}_{2}$ thin film was moved further from $380 \mathrm{~nm}$ in $\mathrm{TiO}_{2}$ thin film to $410 \mathrm{~nm}$ with an increment in the amount of GO. The shifted wavelength indicates that the absorption range of thin-film is broader than that of bare $\mathrm{TiO}_{2}$ thin film with the addition of GO. The addition of GO improved the performance of $\mathrm{TiO}_{2}$ by improving the light adsorption of the thin film as more GO added. The increase in adsorption is because of the low-light scattering. Therefore, this increases the particle size and reduce the size distribution of nanocrystalline ${ }^{39}$ ).

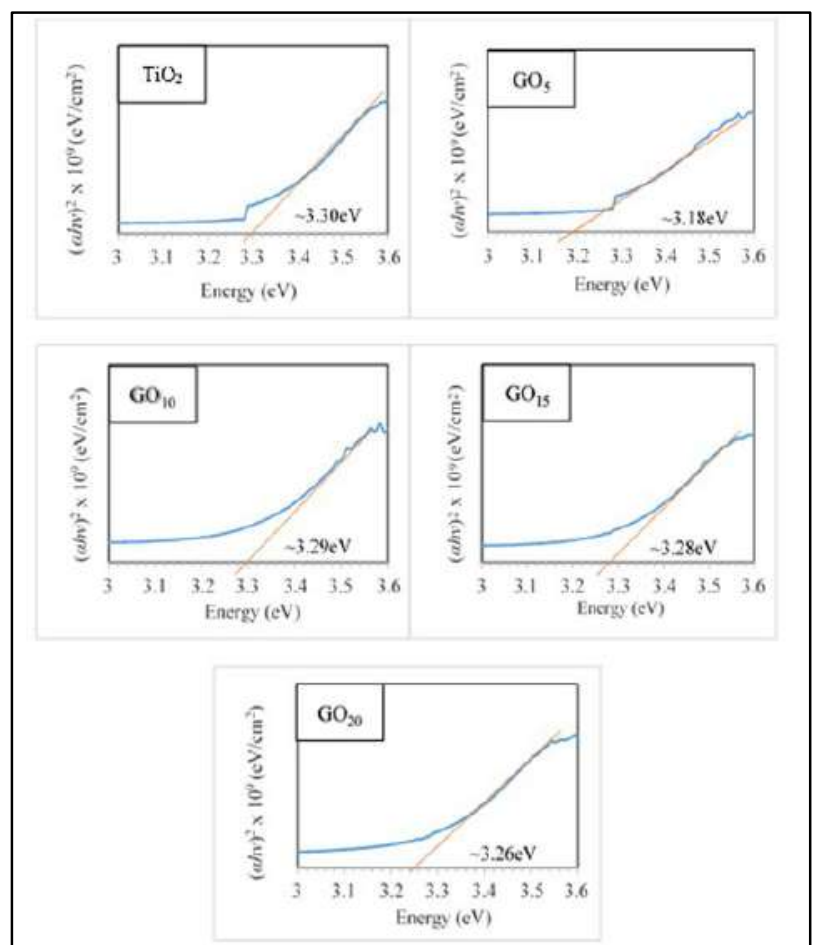

Fig. 5: The energy band gap graph of $\mathrm{TiO}_{2}$ and $\mathrm{GO} / \mathrm{TiO}_{2}$ thin films.
The optical energy gap for the thin films was determined using the Tauc equation given in Eq. (1). Fig. 5 displays the plot $(\alpha h v)^{2}$ versus photon energy $(h v)$ to obtain the $E_{g}$ value for the $\mathrm{GO} / \mathrm{TiO}_{2}$ thin films. Based on the graph, the band gap energy $\left(E_{g}\right)$ value is taken using the straight-line method on the $x$-axis. The lowest energy gap was obtained by $\mathrm{GO}_{5}$, with a value of $3.18 \mathrm{eV}$. As the amount of GO increases from $0 \mathrm{mg}$ to $20 \mathrm{mg}$, the value of the energy gap decreased. This is due to the existence of GO, which permitted the formation of $\mathrm{Ti}^{3+}$ and $\mathrm{O}_{2}$. Therefore, intra gap states could be generated at a low valence state with energy underneath than that in the $\mathrm{TiO}_{2}$ band gap. Therefore, at a higher wavelength, it improved the absorption of light ${ }^{21)}$. The value of the band gap energy and the absorption spectra obtained are complementary to each other. These results suggest that the addition of GO at optimum amount can reduce the width of the gap that is not achieved by $\mathrm{TiO}_{2}$ thin films ${ }^{40}$.

\subsection{Photodegradation Analysis}

Methylene blue dye is a non-toxic and the most suitable dye used to determine $\mathrm{TiO}_{2}$ and $\mathrm{GO} / \mathrm{TiO}_{2}$ thin films' photocatalytic performance. Degradation or decolourization of methylene blue at the wavelength of $664 \mathrm{~nm}$ was applied to measure the photocatalytic performance. This is based on the absorbance value of methylene blue at different time intervals. Thus, Fig. 6 shows a graph plot of $\mathrm{C} / \mathrm{C}_{0}$ against time when the thin films were irradiate under sunlight. The $\mathrm{C}_{0}$ designate the initial concentration, while $\mathrm{C}$ indicates methylene blue (MB) concentration at different irradiation time intervals.

The photodegradation of the samples was carried out for 2.5 hours under sunlight irradiation. Before the photocatalysis process takes place, all the thin film samples were kept in the dark condition for 60 minutes to allow the absorption of methylene blue onto the surface of the films. In Fig. 6, thin films with GO show that it is more effective to degrade methylene blue under sunlight irradiation. After 210 minutes, the $\mathrm{GO}_{20}$ thin film shows a $67 \%$ degradation of methylene blue followed by $\mathrm{GO}_{5}$, $\mathrm{GO}_{10}, \mathrm{GO}_{15}$ and $\mathrm{TiO}_{2}$ with degradation percent of $59 \%$, $56 \%, 55 \%$ and $48 \%$, respectively, as tabulated in Table 1.

Table 1. Percentage of methylene blue absorbance and degradation of $\mathrm{TiO}_{2}$ and $\mathrm{GO} / \mathrm{TiO}_{2}$ thin films.

\begin{tabular}{|c|c|c|}
\hline Samples & $\begin{array}{c}\text { Percentage of } \\
\text { methylene blue } \\
\text { absorbance in the } \\
\text { dark (\%) }\end{array}$ & $\begin{array}{c}\text { Percentage of } \\
\text { methylene blue } \\
\text { degradation under } \\
\text { sunlight irradiation } \\
\text { (\%) }\end{array}$ \\
\hline $\mathrm{TiO}_{2}$ & 10 & 48 \\
\hline $\mathrm{GO}_{5}$ & 10 & 59 \\
\hline $\mathrm{GO}_{10}$ & 14 & 56 \\
\hline $\mathrm{GO}_{15}$ & 12 & 55 \\
\hline $\mathrm{GO}_{20}$ & 37 & 67 \\
\hline
\end{tabular}

$\mathrm{GO}_{20}$ thin film sample shows the highest percentage of 
degradation of methylene blue, which is $67 \%$, while $\mathrm{GO}_{5}$ of $59 \%$ obtained the second-highest degradation. Based on the results, $\mathrm{GO}_{5}$ exhibits the best photocatalytic activity, although $\mathrm{GO}_{20}$ shows a higher degradation efficiency. The higher degradation in the $\mathrm{GO}_{20}$ sample is due to the excellent absorption properties of the catalyst, which means that the photodegradation performance was not outstanding. The results obtained were compatible with the previous research, demonstrating that graphene oxide could be functioning as an adsorbent, electron acceptor, and photosensitizer. This function could also enhance photodecomposition ${ }^{41)}$. The modification made on the $\mathrm{TiO}_{2}$ sample by adding GO improved the photocatalytic degradation of methylene blue in contrast to pure $\mathrm{TiO}_{2}$ thin film. The photogenerated hole and electrons in the modified film were having a lower rate of recombinationand this is the factor that improve the photocatalytic activity. Firthermore, the absorption of methylene blue by GO is also helpful in photocatalytic activity ${ }^{42)}$. However, the excessive quantity of GO decreases the prepared films' photocatalytic activities as the graphene disturbs the light absorption efficiency of $\mathrm{TiO}_{2}{ }^{43)}$.

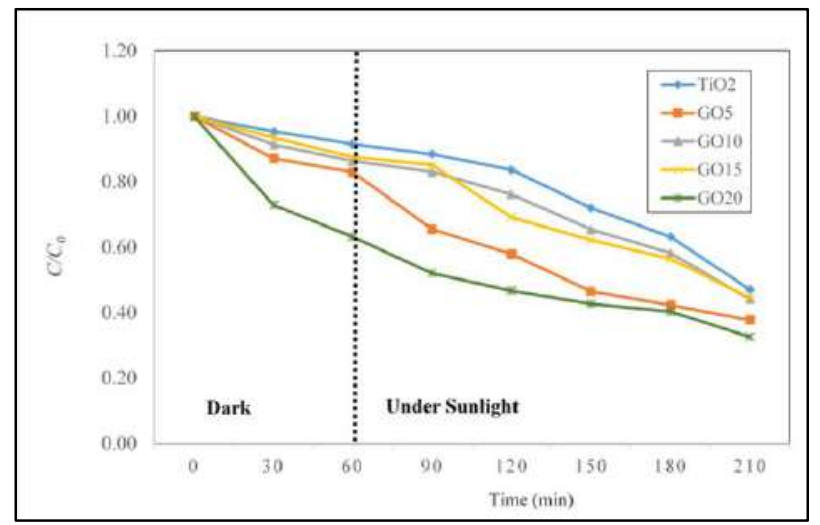

Fig. 6: Photocatalytic degradation efficiency of $\mathrm{TiO}_{2}$ and $\mathrm{GO} / \mathrm{TiO}_{2}$ films.

During the photocatalytic process, the photogenerated electrons can be transferred to the nearby methylene blue while the photocatalysts were excited. It then decomposed the methylene blue into $\mathrm{CO}_{2}$ and $\mathrm{H}_{2} \mathrm{O}$ when the redox reactions take place ${ }^{42)}$. The increased amount of $\mathrm{GO}$ in the resulting film contributes to narrowing the film energy gap and defects.

The proposed possible photocatalysis activity mechanism for the $\mathrm{GO} / \mathrm{TiO}_{2}$ was illustrated in Fig. 7. The photocatalytic degradation mechanism of $\mathrm{GO} / \mathrm{TiO}_{2}$ film occurred via four steps given by:

i. The improved surface of $\mathrm{TiO}_{2}$ by $\mathrm{GO}$ was irradiated under sunlight;

ii. The $\mathrm{e}^{-}$will excite to the conduction band (CB) from the valance band (VB) of $\mathrm{TiO}_{2}$, leaving the $\mathrm{h}^{+}$in the VB;

iii. Firstlt, the $\mathrm{e}^{-}$and $\mathrm{h}^{+}$will reacts with $\mathrm{H}_{2} \mathrm{O}$;

iv. Then, it will induced the degradation of organics.
Equations (3) to (7) explain the degradation of organic compound by $\mathrm{GO} / \mathrm{TiO}_{2}$ films or also know as photocatalytic process is given by:

$\mathrm{GO} / \mathrm{TiO}_{2}+h v \rightarrow \mathrm{e}^{-}+\mathrm{h}^{+}$

The $\mathrm{h}^{+}$generated on the surface of $\mathrm{TiO}_{2}$ reacts with water or hydroxide ions $(\mathrm{OH})^{-}$to generate hydroxyl radicals $(\mathrm{OH} \bullet)$, and the generated $\mathrm{e}^{-}$reacts with $\mathrm{O}_{2}$ to generate superoxide $\left(\mathrm{O}_{2} \bullet\right)^{-}$.

$$
\begin{aligned}
& \mathrm{HO}_{2}+\mathrm{h}^{+} \rightarrow \mathrm{OH}^{\cdot}+\mathrm{H}^{+} \\
& \mathrm{OH}^{-}+\mathrm{h}^{+} \rightarrow \mathrm{OH}^{-} \\
& \mathrm{O}_{2}+\mathrm{e}^{-} \rightarrow \mathrm{O}_{2}^{\cdot-} \\
& \mathrm{OH} . / \mathrm{O}_{2}^{\cdot} \cdot / \mathrm{h}^{+}+\text {organics } \rightarrow \text { degraded } \\
& \text { products }
\end{aligned}
$$

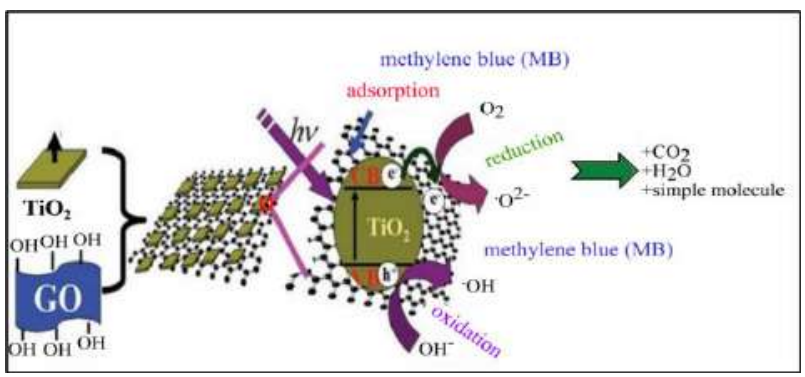

Fig. 7: Schematic diagram of proposed photocatalytic activity of and methylene blue degradation of $\mathrm{GO} / \mathrm{TiO}_{2}$ film under sunlight irradiation ${ }^{45)}$.

\section{Conclusion}

Successfully produced $\mathrm{GO} / \mathrm{TiO}_{2}$ thin film was synthesized via sol-gel method with spin coating deposition technique to be used as a self-cleaning coating. Characterization of the thin films exhibiting the anatase phase of $\mathrm{TiO}_{2}$ formed with GO introduction. Meanwhile, the microstructure of the $\mathrm{TiO}_{2}$ thin film changes when the GO is added to the thin film. The photodegradation performance of the thin film was investigated using methylene blue under sunlight irradiation. The prepared thin film coating exhibits super hydrophilic properties with a $4.11^{\circ}$ water contact angle and lower band gap of $\mathrm{TiO}_{2}$ from $3.30 \mathrm{eV}$ to $3.18 \mathrm{eV}$. Therefore, this resulted in more excellent absorption, enhancing the photodegradation performance due to the synergistic effects between $\mathrm{GO}$ and $\mathrm{TiO}_{2}$, which degraded about $59 \%$ of methylene blue.

\section{Acknowledgements}

The authors wish to express their gratitude to the Center of Excellence Geopolymer \& Green Technology (CEGeoGTech), Universiti Malaysia Perlis, UniMAP and Faculty of Chemical Engineering Technology Universiti Malaysia Perlis, UniMAP for their partial support. Most importantly, the authors would like to acknowledge the support received from the Ministry of Education under the 
Fundamental Research Grant Scheme (FRGS) with a grant number of FRGS/1/2017/TK07/UNIMAP/02/6 and another grant number 9002-0082 from Tin Board Industry Grant

\section{Nomenclature}

\begin{tabular}{|l|l|}
\hline $\mathrm{GO}$ & Graphene oxide \\
\hline $\mathrm{TiO}_{2}$ & Titanium dioxide \\
\hline $\mathrm{WCA}$ & Water contact angle \\
\hline $\mathrm{UV}$ & Ultraviolet \\
\hline $\mathrm{UV}-$ Vis & Ultraviolet-visible \\
\hline $\mathrm{rpm}$ & Rotation per minute \\
\hline $\mathrm{eV}$ & Electrovolt \\
\hline$h v$ & Photon energy \\
\hline$\alpha$ & alpha \\
\hline $\mathrm{Eg}$ & Band gap energy \\
\hline$C_{0}$ & Initial concentration \\
\hline$C$ & Concentration \\
\hline
\end{tabular}

\section{References}

1) M.M. Mahlambi, C.J. Ngila, and B.B. Mamba, "Recent developments in environmental photocatalytic degradation of organic pollutants: the case of titanium dioxide nanoparticles-a review," $J$. Nanomater., (2015). doi:10.1155/2015/790173.

2) K. Taira, and H. Einaga, "Distribution ratio of pt on anatase and rutile $\mathrm{TiO}_{2}$ particles, determined by x-ray diffraction and transmission electron microscopy analysis of $\mathrm{Pt} / \mathrm{TiO}_{2}(\mathrm{p} 25)$,” Evergreen, 5 (4) 13-17 (2018). doi:10.5109/2174853.

3) A. Timoumi, S.N. Alamri, and H. Alamri, "The development of $\mathrm{TiO}_{2}$-graphene oxide nano composite thin films for solar cells," Results Phys., 11 46-51 (2018). doi:10.1016/j.rinp.2018.06.017.

4) J. Wen, X. Li, W. Liu, Y. Fang, J. Xie, and Y. Xu, "Photocatalysis fundamentals and surface modification of $\mathrm{TiO}_{2}$ nanomaterials," Chinese $\mathrm{J}$. Catal., $36 \quad$ (12) 2049-2070 (2015). doi:10.1016/S1872-2067(15)60999-8.

5) J. Chen, F. Qiu, W. Xu, S. Cao, and H. Zhu, "Recent progress in enhancing photocatalytic efficiency of $\mathrm{TiO}_{2}$-based materials," "Applied Catal. A, Gen., (2015). doi:10.1016/j.apcata.2015.02.013.

6) M.K. Tariq, A. Riaz, R. Khan, A. Wajid, H.U. Haq, S. Javed, M.A. Akram, and M. Islam, "Comparative study of Ag, Sn or $\mathrm{Zn}$ doped $\mathrm{TiO}_{2}$ thin films for photocatalytic degradation of methylene blue and methyl orange,” Mater. Res. Express, 6 (10) (2019). doi:10.1088/2053-1591/ab3efd.

7) T. Shirahata, T. Kawaharamura, S. Fujita, and H. Orita, "Transparent conductive zinc-oxide-based films grown at low temperature by mist chemical vapor deposition,” Thin Solid Films, 597 30-38 (2015). doi:10.1016/j.tsf.2015.11.006.

8) M. Pawar, S.T. Sendoğdular, and P. Gouma, “A brief overview of $\mathrm{TiO}_{2}$ photocatalyst for organic dye remediation: case study of reaction mechanisms involved in $\mathrm{Ce}-\mathrm{TiO}_{2}$ photocatalysts system," $J$. Nanomater., $2018 \quad 1-13 \quad$ (2018). doi:10.1155/2018/5953609.

9) J.T.W. Wang, J.M. Ball, E.M. Barea, A. Abate, J.A. Alexander-Webber, J. Huang, M. Saliba, I. MoraSero, J. Bisquert, H.J. Snaith, and R.J. Nicholas, "Low-temperature processed electron collection layers of graphene/ $\mathrm{TiO}_{2}$ nanocomposites in thin film perovskite solar cells,” Nano Lett., 14 (2) (2014). doi:10.1021/nl403997a.

10) I.H. Dwirekso, M. Ibadurrohman, and Slamet, "Synthesis of $\mathrm{TiO}_{2}-\mathrm{SiO}_{2}-\mathrm{CuO}$ nanocomposite material and its activities for self-cleaning," Evergreen, 7 (2) 285-291 (2020).

11) M. Ezaki, and K. Kusakabe, "Highly crystallized tungsten trioxide loaded titania composites prepared by using ionic liquids and their photocatalytic behaviors," Evergreen, 1 (2) 18-24 (2014). doi:10.5109/1495159.

12) W. Sangchay, “The self-cleaning and photocatalytic properties of $\mathrm{TiO}_{2}$ doped with sno2thin films preparation by sol-gel method,” Energy Procedia, 89 170-176 (2016). doi:10.1016/j.egypro.2016.05.023.

13) D.S.C. Halin, M.M.A.B. Abdullah, N. Mahmed, S.N.A. Abdul Malek, P. Vizureanu, and A.W. Azhari, "Synthesis and characterization of $\mathrm{TiO}_{2} / \mathrm{SiO}_{2}$ thin film via sol-gel method," IOP Conf. Ser. Mater. Sci. Eng., $209 \quad$ (1) (2017). doi:10.1088/1757899X/209/1/012002.

14) M. Nasirian, C.F. Bustillo-Lecompte, and $M$. Mehrvar, "Photocatalytic efficiency of $\mathrm{Fe}_{2} \mathrm{O}_{3} / \mathrm{TiO}_{2}$ for the degradation of typical dyes in textile industries: effects of calcination temperature and uvassisted thermal synthesis,” J. Environ. Manage., 196 487-498 (2017). doi:10.1016/j.jenvman.2017.03.030.

15) Q. Mei, F. Zhang, N. Wang, Y. Yang, R. Wu, and W. Wang, " $\mathrm{TiO}_{2} / \mathrm{Fe}_{2} \mathrm{O}_{3}$ heterostructures with enhanced photocatalytic reduction of cr(vi) under visible light irradiation,” RSC Adv., 9 (39) 22764-22771 (2019). doi:10.1039/c9ra03531a.

16) B. Pant, H.R. Pant, N.A.M. Barakat, M. Park, K. Jeon, Y. Choi, and H.Y. Kim, "Carbon nanofibers decorated with binary semiconductor $\left(\mathrm{TiO}_{2} / \mathrm{ZnO}\right)$ nanocomposites for the effective removal of organic pollutants and the enhancement of antibacterial activities,” Ceram. Int., 39 (6) 7029-7035 (2013). doi:10.1016/j.ceramint.2013.02.041.

17) S. Samadi, S. Samadi, R. Ahmadi, and M. Kohi, 
"Nanocomposite thin film as visible-light active photocatalyst,” Int. J. New Chem., 2 (January) 179187 (2015).

18) L. Fu, T. Xia, Y. Zheng, J. Yang, A. Wang, and Z. Wang, "Preparation of $\mathrm{WO}_{3}$-reduced graphene oxide nanocomposites with enhanced photocatalytic property,” Ceram. Int., 41 (4) (2015). doi:10.1016/j.ceramint.2015.01.022.

19) H.-Y. He, Z. He, and Q. Shen, "Fabrication and selfcleaning properties of reduced graphene oxide/ $\mathrm{TiO}_{2}$ :Nd nanohybrid thin films," Part. Sci. Technol., $6351 \quad 1-7 \quad$ (2018). doi:10.1080/02726351.2017.1414090.

20) M.I. Baig, P.G. Ingole, J. deok Jeon, S.U. Hong, W.K. Choi, and H.K. Lee, "Water vapor transport properties of interfacially polymerized thin film nanocomposite membranes modified with graphene oxide and $\mathrm{GO}-\mathrm{TiO}_{2}$ nanofillers," Chem. Eng. J., 373 (April) 1190-1202 doi:10.1016/j.cej.2019.05.122.

(2019).

21) W. Vallejo, W. Vallejo, A. Rueda, C. D1, C. Grande, and P. Quintana, "Photocatalytic activity of graphene oxide- $\mathrm{TiO}_{2}$ thin films sensitized by natural dyes extracted from bactris guineensis," R. Soc. Open Sci., $6181824 \quad$ (2019). doi:http://dx.doi.org/10.1098/rsos.181824.

22) A. Jalaukan, S.M. Aldowaib, A.S. Hamed, B. Ghanbari Shohany, R. Etefagh, and A. Khorsand Zak, "Photocatalytic activity, antibacterial effect, and self cleaning properties of $\mathrm{TiO}_{2} / \mathrm{GO}$ thin films," Iran. J. Mater. Sci. Eng., 16 (4) 53-62 (2019). doi:10.22068/ijmse.16.4.53.

23) A.S. Idris, S. Ghosh, H. Jiang, and K. Hamamoto, “A multi-layer stacked all sol-gel fabrication technique for vertical coupled waveguide,” Evergreen, 4 (2-3) 12-17 (2017). doi:10.5109/1929657.

24) K. Abdul Razak, D. Suriyani Che Halin, A. Azani, M. Mustafa Al Bakri Abdullah, M. Arif Anuar Mohd Salleh, N. Mahmed, M. Mahyiddin Ramli, and S. Sepeai, "Mesoporous structure of doped and undoped peg on $\mathrm{Ag} / \mathrm{TiO}_{2}$ thin film,” IOP Conf. Ser. Mater. Sci. Eng., $551 \quad$ (1) (2019). doi:10.1088/1757899X/551/1/012098.

25) A.T. Dideikin, and A.Y. Vul', "Graphene oxide and derivatives: the place in graphene family," Front. Phys., 6 (JAN) (2019). doi:10.3389/fphy.2018.00149.

26) A.S. Bakri, M.Z. Sahdan, F. Adriyanto, N.A. Raship, N.D.M. Said, S.A. Abdullah, and M.S. Rahim, "Effect of annealing temperature of titanium dioxide thin films on structural and electrical properties,” in: AIP Conf. Proc., 2017: p. 030030. doi:10.1063/1.4968283.

27) S. Bakardjieva, V. Stengl, L. Szatmary, J. Subrt, J. Lukac, N. Murafa, D. Niznansky, K. Cizek, J. Jirkovsky, and N. Petrova, "Transformation of brookite-type $\mathrm{TiO}_{2}$ nanocrystals to rutile: correlation between microstructure and photoactivity,” J. Mater.
Chem., $16 \quad$ (18) 1709-1716 (2006). doi:10.1039/b514632a.

28) K. Fischer, A. Gawel, D. Rosen, M. Krause, A.A. Latif, J. Griebel, A. Prager, and A. Schulze, "Lowtemperature synthesis of anatase/rutile/brookite $\mathrm{TiO}_{2}$ nanoparticles on a polymer membrane for photocatalysis," Catalysts, $\quad 7 \quad 1-14 \quad$ (2017). doi:10.3390/catal7070209.

29) N.D. Johari, Z.M. Rosli, J.M. Juoi, and S.A. Yazid, "Comparison on the $\mathrm{TiO}_{2}$ crystalline phases deposited via dip and spin coating using green sol-gel route," J. Mater. Res. Technol., 8 (2) 2350-2358 (2019). doi:10.1016/j.jmrt.2019.04.018.

30) A. Guimont, E. Beyou, P. Cassagnau, G. Martin, P. Sonntag, F. D’Agosto, and C. Boisson, "Grafting of polyethylene onto graphite oxide sheets: a comparison of two routes," Polym. Chem., 4 (9) 2828-2836 (2013). doi:10.1039/c3py00160a.

31) J.L.S. Gascho, S.F. Costa, A.A.C. Recco, and S.H. Pezzin, "Graphene oxide films obtained by vacuum filtration: x-ray diffraction evidence of crystalline reorganization,” J. Nanomater., 2019 12-16 (2019). doi:10.1155/2019/5963148.

32) Y. Ni, W. Wang, W. Huang, C. Lu, and Z. Xu, "Graphene strongly wrapped $\mathrm{TiO}_{2}$ for high-reactive photocatalyst: a new sight for significant application of graphene,” J. Colloid Interface Sci., 428 162-169 (2014). doi:10.1016/j.jcis.2014.04.022.

33) Y. Zhang, Z.-R. Tang, X. Fu, and Yi-Jun Xu, “TiO2graphene nanocomposites for gas phase degradation of volatile aromatic pollutant: is tio2-graphene truly different from other $\mathrm{TiO}_{2}$-carbon composite materials?,” ASC Nano, 4 (12) 7303-7314 (2010).

34) M.A.M.L. de Jesus, J.T. da S. Neto, G. Timò, P.R.P. Paiva, M.S.S. Dantas, and A. de M. Ferreira, "Superhydrophilic self-cleaning surfaces based on $\mathrm{TiO}_{2}$ and $\mathrm{TiO}_{2} / \mathrm{SiO}_{2}$ composite films for photovoltaic module cover glass,” Appl. Adhes. Sci., 3 (1) 1-9 (2015). doi:10.1186/s40563-015-0034-4.

35) M. Hashemi, B. Muralidharan, M. Omidi, J. Mohammadi, Y. Sefidbakht, E.S. Kima, H.D.C. Smyth, M. Shalbaf, and T.E. Milner, "Effect of size and chemical composition of graphene oxide nanoparticles on optical absorption cross-section," $J$. Biomed. Opt., $23 \quad$ (8) 1-9 (2018). doi:10.1117/1.jbo.23.8.085007.

36) B. Pant, N.A.M. Barakat, H.R. Pant, M. Park, P.S. Saud, J.W. Kim, and H.Y. Kim, "Synthesis and photocatalytic activities of $\mathrm{Cds} / \mathrm{TiO}_{2}$ nanoparticles supported on carbon nanofibers for high efficient adsorption and simultaneous decomposition of organic dyes,” J. Colloid Interface Sci., 434 159-166 (2014). doi:10.1016/j.jcis.2014.07.039.

37) B. Pant, P.S. Saud, M. Park, S.J. Park, and H.Y. Kim, "General one-pot strategy to prepare Ag- $\mathrm{TiO}_{2}$ decorated reduced graphene oxide nanocomposites for chemical and biological disinfectant,” Elsevier 
Ltd, 2016. doi:10.1016/j.jallcom.2016.02.067.

38) A.E. Athare, "Synthesis, characterization and antimicrobial activity of sulphur doped $\mathrm{ZnO}$ nanoparticals,” IJSRSET, 4 (1) 632-636 (2018).

39) W. Sun, S. Zhang, Z. Liu, C. Wang, and Z. Mao, "Studies on the enhanced photocatalytic hydrogen evolution over Pt/PEG-modified $\mathrm{TiO}_{2}$ photocatalysts," Int. J. Hydrogen Energy, 33 (4) 1112-1117 (2008). doi:10.1016/j.ijhydene.2007.12.059.

40) V. Štengl, S. Bakardjieva, T.M. Grygar, J. Bludská, and M. Kormunda, " $\mathrm{TiO}_{2}$-graphene oxide nanocomposite as advanced photocatalytic materials," Chem. Cent. J., 7 (41) 1-12 (2013). doi:10.1186/1752-153X-7-41.

41) V.H. Pham, E.W. Shin, H. Pham, S. Kim, J.S. Chung, E.J. Kim, and S.H. Hur, "The role of graphene oxide content on the adsorption-enhanced photocatalysis of titanium dioxide/ graphene oxide composites," Chem. Eng. J., $\quad \mathbf{1 7 0} \quad$ (1) 226-232 (2011). doi:10.1016/j.cej.2011.03.060.

42) H. Atout, M.G. Álvarez, D. Chebli, A. Bouguettoucha, D. Tichit, J. Llorca, and F. Medina, "Enhanced photocatalytic degradation of methylene blue: preparation of $\mathrm{TiO}_{2}$ /reduced graphene oxide nanocomposites by direct sol-gel and hydrothermal methods,” Mater. Res. Bull., 95 578-587 (2017). doi:10.1016/j.materresbull.2017.08.029.

43) A. Tayel, A.R. Ramadan, and O.A. El Seoud, "Dioxide/graphene oxide nanocomposites : synthesis, water decontamination,” Catalyst, 8 (491) 1-45 (2018). doi:10.3390/catal8110491.

44) I. ALI, S.-R. KIM, K. PARK, and JONG-OH KIM, "One-step electrochemical synthesis of graphene oxide- $\mathrm{TiO}_{2}$ nanotubes for improved visible light activity,” Opt. Mater. Express, 7 (5) 159-166 (2017). https://doi.org/10.1364/OME.7.001535.

45) K. Dai, L. Lu, Q. Liu, G. Zhu, Q. Liu, and Z. Liu, " $\mathrm{TiO}_{2}$ nanosheets for advanced photocatalysis and," R. Soc. Chem. Trans., 43 (5) 2202-2210 (2014). doi:10.1039/c3dt52542b. 